University of Nebraska - Lincoln

DigitalCommons@University of Nebraska - Lincoln

2020

\title{
Motivated viewing: Selective exposure to political images when reasoning is not involved
}

\author{
Clarisse Warren \\ University of Nebraska-Lincoln, clarisse.warren@huskers.unl.edu \\ Stephen Schneider \\ University of Nebraska-Lincoln \\ Kevin Smith \\ University of Nebraska - Lincoln, ksmith1@unl.edu \\ John Hibbing \\ University of Nebraska-Lincoln, jhibbing1@unl.edu
}

Follow this and additional works at: https://digitalcommons.unl.edu/poliscifacpub

Part of the Political Science Commons

Warren, Clarisse; Schneider, Stephen; Smith, Kevin; and Hibbing, John, "Motivated viewing: Selective exposure to political images when reasoning is not involved" (2020). Faculty Publications: Political Science. 115.

https://digitalcommons.unl.edu/poliscifacpub/115

This Article is brought to you for free and open access by the Political Science, Department of at DigitalCommons@University of Nebraska - Lincoln. It has been accepted for inclusion in Faculty Publications: Political Science by an authorized administrator of DigitalCommons@University of Nebraska - Lincoln. 


\title{
Motivated viewing: Selective exposure to political images when reasoning is not involved
}

\author{
Clarisse Warren, Stephen Schneider, \\ Kevin B. Smith, John R. Hibbing \\ University of Nebraska-Lincoln, Lincoln, NE 68588-0328 United States \\ Corresponding author - K. B. Smith \\ Email addresses - clarisse.warren@huskers.unl.edu (C. Warren), \\ ksmith1@unl.edu (K.B. Smith), Jhibbing1@unl.edu
}

\begin{abstract}
Motivated reasoning is an important element of politics especially in these highly polarized times. People selectively expose themselves to information in a fashion that makes it possible to embrace arguments consistent with their existing biases and ignore arguments inconsistent with those biases. Often overlooked in the research on motivated reasoning and selective exposure to information, however, is that a substantial portion of politics is about affective responses-that which makes people feel good and that which makes people feel bad. In this paper, we introduce a novel indicator of people's tendency to prolong exposure to favored political images or to truncate exposure to disliked political images. This measure makes it possible to better understand individual differences regarding concepts such as negativity bias and asymmetric political attention even when substantive, issue-based information is not at play.
\end{abstract}

Keywords: Motivated reasoning. Selective exposure, Keypress

Published in Personality and Individual Differences 155 (2020) 109704

DOI:10.1016/j.paid.2019.109704.

Copyright (C) 2019 Elsevier Ltd. Used by permission.

Submitted 28 May 2019; revised 4 November 2019; accepted 8 November 2019; published 22

November 2019. 
Rearch consistently demonstrates that people engage in motivated -reasoning, in part by selectively exposing themselves to information and arguments consistent with their pre-existing biases while minimizing exposure to inconsistent information and arguments (Leeper \& Mullinix, 2018). Research also demonstrates that politics is about affect - the feelings and emotions produced by a given stimulus (Crigler \& Hevron, 2017). Indeed, Lodge and Taber (2013) suggest that every politically relevant stimulus carries an affective tag, and this affective tag on political leaders, groups, and issues is automatic in nature (Lodge \& Taber, 2005) and provides an underlying motivation for cognitive and behavioral responses to any given political stimulus.

Selective exposure is broadly assumed to be concerned with the degree to which people are and are not open to substantive information (Hart et al., 2009). Left unclear is the degree to which selective exposure is influenced by affect. Do people screen stimuli that are affective but devoid of political issue-based content in the same way they screen information that is more substantive and policy-driven? If they do, much of what appears to be motivated reasoning may actually be motivated viewing, (i.e. an approach/avoid behavioral or cognitive response anchored in an automatic affective response to a visual stimulus).

If, in addition to being motivated reasoners, people are also motivated viewers, efforts to improve the polity by disseminating balanced and objective information are likely to be less successful than anticipated. Accordingly, our objective here is to investigate how much effort people are willing to expend to view non-informational political material they favor and to remove non-informational political material they dislike. We do so primarily by introducing an adapted measure of effort made to alter exposure to political stimuli.

\section{Measuring selective exposure to political content}

Festinger's (1957) influential work on cognitive dissonance set the stage for analyses of selective exposure, which has been defined as "the tendency to craft an information environment that reflects one's political beliefs" (Garrett, 2009, 677). This is important because exposure to different and opposing views is intimately connected to democracy and to tolerance (see, for example, Arceneaux \& Johnson, 2013; Huckfeldt, 
Johnson \& Sprague, 2004; Mondak, Hibbing, Canache, Seligson \& Anderson, 2010; Mutz, 2002, 2006; Sunstein, 2001).

An important dispute has arisen over the two elements of selective exposure: seeking confirmatory information and avoiding disconfirmatory information. Are people as likely to engage in challenge avoidance as they are to engage in reinforcement seeking? The extensive literatures on approach and avoidance behavior (Feltman \& Elliot, 2012; Lee et al., 2015), regulatory focus theory (Brockner \& Higgins, 2001), and loss aversion (Kahneman \& Tversky, 1984; Kim et al., 2010) suggest that challenge avoidance will be the stronger tendency. Yet, several studies on selective exposure find less evidence of challenge avoidance even while confirming that people seek confirming information (Frey, 1986; Garrett, 2009). The explanation for this finding harkens back to Festinger's (1957) point that, while opinion reinforcing information makes people feel good, opinion-challenging information, even if negatively valenced, still provides information and is unlikely to be completely avoided. Additionally, recent research has demonstrated that there is a great deal of variation in negativity bias (Soroka, Fournier, Nir \& Hibbing, 2019), but much of the negativity bias literature fails to provide alternatives to attention - such as ways to avoid the negative or displeasing information, images, videos, or other stimuli.

Another heavily researched topic is individual-level variation in the tendency to engage in selective exposure. Partisan and ideological differences seem to play a role (Gerber, Huber, Doherty \& Dowling, 2012; Jost \& Amodio 2012), and those with more intense or extreme political beliefs appear to be most prone to engage in selective exposure (Feldman, Stroud, Bimber \& Wojcieszak, 2013). Electoral context has also been shown to influence the degree to which partisanship influences selective exposure (Knobloch-Westerwick \& Kleinman, 2012).

We focus here on the motivations that drive selective exposure. Given the tribal nature of modern American politics, it may be that, information aside, people engage in selective exposure out of a desire to expose themselves to fellow partisans while minimizing their exposure to those they find distasteful. People may not be seeking an imbalanced informational environment so much as they are maneuvering toward affectively pleasing situations and experiences and/or away from affectively displeasing situations and experiences.

To explore the many issues surrounding affective selective exposure, we need a measure that possesses several qualities. First, given people's 
well-known tendency to put a favorable spin on their behaviors, a behavioral rather than self-report measure is needed. Second, the measure must allow us to separately identify desires to prolong exposure to stimuli with positive affect from desires to minimize exposure to stimuli that are unpalatable. Third, the measure should tap into the effort people are willing to expend in prolonging or truncating exposure. Merely providing participants the opportunity to select the content they want to see and not see, as standard measurement approaches do, does not tell the full story as people often are in a position where they must take action in order to minimize their exposure to disliked political stimuli - whether it be navigating away from a website or reporting disliked advertisements on social media. Echo chamber effects may not fully account for a realistic, multiple media environment (Dubois \& Blank, 2018) in which people are consistently presented with information they find pleasing and displeasing. Therefore, a measure not centered on choice, but rather in the effort people expend to navigate toward or away from content they want to see and not see is needed. Fourth, the measure should be able to identify selective exposure when overt, issue-based information is not in play. Finally, the measure should be subject to reasonable controls and manipulations. We believe there is a measure of effort, developed by Kim et al. (2010) and called the keypress task, which meets the aforementioned demands (alternative measurement strategies are described in DiMaggio \& Sato, 2003; Holtzman, Schott, Jones, Balota \& Yarkoni, 2011; Marquart, Matthes \& Rapp, 2016).

Our adaptation of the keypress task to test for selective political exposure worked as follows. Subsequent to granting informed consent, participants were brought into a laboratory setting and instructed that they would encounter a series of images on a computer screen over the course of twenty minutes. All participants were shown the same $72 \mathrm{im}$ ages and the images and blocks were randomized. Similar to Kim et al. (2010), participants were instructed that they would see a flash of the upcoming image (200 ms), followed, in order, by a $1.8 \mathrm{~s}$ focal point, a displayed image with a default time of $8 \mathrm{~s}$, and a $1.5 \mathrm{~s}$ black screen between each image. The display time was adjusted to account for both the complexity of the images, and the degree to which pilot tests found their effort to extend or truncate viewing rewarding. This process repeated until the twenty minutes was over.

If the participant opted to press no keys, each image remained on the screen for eight seconds. To get the image to disappear before $8 \mathrm{~s}$ 
elapsed, the participant needed to alternate pressing keys " $\mathrm{X}$ " and "M" on the keyboard. Each key sequence pressed reduced the display time of the image by a small fraction of a second, such that the absolute minimum amount of time the image could be seen was four seconds. If the participant wanted to keep the image on the screen longer than the default $8 \mathrm{~s}$, keys "S" and "K" had to be pressed in an alternating fashion, which added a small fraction of a second for each press. The maximum view time possible was twelve seconds.

Participants encountered four blocks of images (political actors, political issue images, positive and negative images, and pleasing and displeasing faces), but only two blocks are used for this project: political actors and generic (that is, non-political) positive and negative images. The generic positive and negative images were obtained from the International Affective Picture System (IAPS) and were selected based on their mean arousal and mean valence pre-rated scores (Lang, Bradley \& Cuthbert, 1997). Unlike the generic images, the valence of political images will depend on the partisan and ideological affinities of the individuals viewing the images. We selected images of prominent Democrat and Republican politicians and assumed that Democrats would be more likely to view favorably images of Hillary Clinton, Barack Obama and Bernie Sanders and to view unfavorably images of Donald Trump, Ted Cruz, and Mitch McConnell; Republicans, the opposite.

Following the keypress task, participants were shown each image again and asked to report their valence and arousal. Additionally, participants were asked to report whether they recognized each politician and whether s/he was a Republican or Democrat. Participants were then asked to answer a series of survey items capturing their demographic traits, ideological and partisan identifications, and policy preferences on salient issues. Psychological batteries in the survey included a measure of risk-taking tendencies, the Big 5 personality traits (DeYoung, Quilty \& Peterson, 2007), and behavioral inhibition/behavioral activation systems (Carver \& White, 1994).

For each image presented, the primary variable is the amount of effort expended to either prolong or shorten exposure, operationalized as the number of " $\mathrm{S}-\mathrm{K}$ " keypresses minus the number of "X-M" keypresses during viewing of the image in question. Positive values indicate an overall effort to prolong viewing of the image; negative values an overall effort to shorten exposure to the image. (Programming syntax for the keypress task is available to interested scholars who contact the authors.) 


\section{Hypotheses}

Drawing on cognitive dissonance theory and following the findings of Kim et al. (2010) we hypothesize that participants will expend effort to prolong exposure to images they view positively and will also expend effort to truncate exposure to images they view negatively. As the extensive literature on negativity bias suggests, however, these two tendencies may not be symmetrical (see Peeters \& Czapinski, 1990); however, negativity bias is universal and individual variation in negativity bias exists (Soroka et al., 2019). Traditional conceptualizations of negativity bias would expect people to maintain exposure of negative images, perhaps as a way of exerting vigilance. However, we believe that by providing participants with a way to escape the negative, they will be more likely to do so. Recent research has demonstrated that when provided alternatives, dwell time viewing negative images is lessened (Oosterhoff, Shook \& Ford, 2018). Thus, we expect that, on balance, people will expend more effort to remove the negative than they will to prolong the positive. Participants are likely to display political tribalism by prolonging viewing of "own party" images and, to an even greater degree, truncating viewing of "other party" images. We also hypothesize that patterns of effort in the face of generic images will parallel those found for political images and that people's self-reported responses to positive and negative stimuli will correlate with their willingness to expend effort to prolong or shorten exposure to those particular stimuli.

Several other hypotheses address individual variation. Distinct psychological orientations are likely to lead to important differences in how the participants interact with the political environment. For example, psychologists have long recognized the important distinction between approach and avoidance behaviors (Feltman \& Elliot, 2012), and these differences have been measured with a validated battery that distinguishes between people oriented toward making good things happen as opposed to keeping bad things from happening (Carver \& White, 1994). These same distinct tendencies are likely to be on display in the political realm with some individuals driven primarily by the desire to view preferred candidates and parties and others driven primarily by the desire to defeat disliked candidates and parties. We hypothesize that individuals who are approach oriented will work harder to prolong exposure to favorable images and that individuals who are inhibition oriented will work harder at truncating exposure to unfavorable images. 
The survey also included the short version of the Big Five Personality battery (TIPI). We have no clear expectations for any relationship between openness, conscientiousness, extraversion, agreeableness, or neuroticism and the various measures of effort. However, as research has demonstrated, such individual-level differences are likely to influence political orientation (Gerber, Huber, Doherty, Dowling \& Ha, 2010; Mondak et al., 2010) and intensity of political identification (Gerber et al., 2012; see also Bakker, Hopmann \& Persson, 2015 for review); therefore, we expect that these factors may also impact the degree to which individuals exert effort, particularly for political stimuli. Given that previous research has demonstrated the effect of personality traits on information receiving and political behavior, we believe that exploration of personality in relation to task behaviors are of interest and pertinent to understanding individual variation in keypress behavior.

Similarly, individual variation in the degree to which people are likely to approach or avoid various types of information should be considered; therefore, we include measures of behavioral approach and avoidance, as is captured by inclusion of the Behavioral Inhibition Scale/Behavioral Activation Scale (BIS/BAS). Examination of variation on approach and avoidance may provide additional context to understanding whether certain types of people may be more likely to engage in motivated viewing. The standard array of demographics is available as controls.

The variables of most interest, however, are those pertaining to political beliefs and behaviors. Asymmetry between those on the left and those on the right is a salient topic of late. Previous literature suggests that, relative to liberals, conservatives tend to have a stronger negativity bias (Oxley et al., 2008; Shook \& Fazio, 2009). This finding supports the hypothesis that conservatives will expend more effort to minimize their exposure to unfavorable images.

Moreover, any ideological pattern in keypress behavior should not necessarily be expected to apply equally in the generic as well as the political realm. Previous research consistently finds that motivated reasoning, intolerance, and dislike for the other side is just as palpable among liberals as it is among conservatives (Brandt, Reyna, Chambers, Crawford \& Wetherell, 2014; Crawford, Modri \& Motyl, 2013). As such, those on the left and those on the right should be roughly equal in their willingness to exert effort to prolong viewing of their own side's politicians and to shorten viewing of politicians belonging to the other side even as those on the political right may be more likely to avoid displeasing generic images. 
Ideological asymmetries aside, we hypothesize a positive correlation between extremity of political beliefs and effort in response to the political images, especially the "other party" images. Political orientations more distant from the ideological center should be accompanied by a desire to make the politically undesirable go away and, to a lesser extent, by the desire to make the politically desirable stay longer. If we are correct and the people most prone to extreme political beliefs are also more inclined to fixate on the opposition, this might help to explain the salient role of the negative in the political arena and news concerning it (Soroka \& McAdams, 2015).

\section{Results}

All participants consented to participate in the study in accordance with the guidelines of the Institutional Review Board of [institution]. Our sample consisted of 130 students enrolled in introductory-level political science classes in March of 2018.

Summaries of the keypress behavior of the participants are presented in Fig. 1. (We replicated these general patterns in a smaller student sample, where students completed the same task a year later, and these results are presented in the appendix to provide evidence of the stability of the findings). Here we see the mean effort participants made to keep the generic pleasant images on the screen and the mean effort participants made to abbreviate exposure to the unpleasant images. As expected, participants worked to lengthen exposure to generic positive images (e.g., a beautiful sunset) and worked to lessen exposure to generic unpleasant images (e.g., a used toilet). The mean activity to prolong positively rated images was 4.2 keypresses per second while the mean absolute value of activity to remove negatively rated images was 5.7 keypresses per second ( $p<.01$, two-tailed $t$-test using absolute values).

Moving to the political images, we showed participants the images of 15 political figures, 8 Republicans, including two images of Donald Trump, and 7 Democrats, including two images of Hillary Clinton. In Table 1, we present the keypress activity engaged in by Democratic participants and Republican participants while they viewed the 17 images of politicians. To provide context, we also present the percent of participants (Republican and Democrats combined) who claimed to recognize each of the images. 


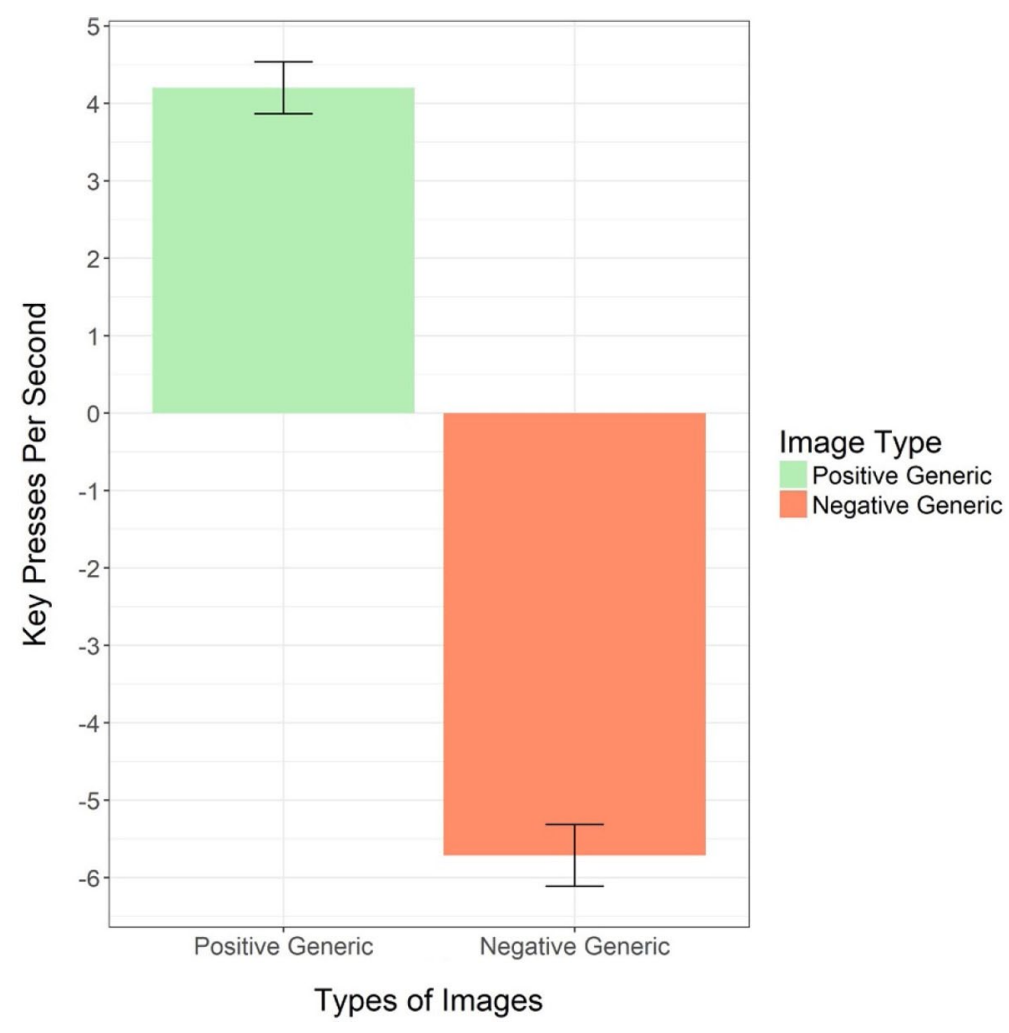

Fig. 1. Keypress activity during viewing of positive and negative generic images.

The 55 Republican participants worked hardest to remove the two images of Hillary Clinton followed by Bill Clinton, Bernie Sanders, and Nancy Pelosi. On the other hand, they did not make much effort to shorten their exposure to Joe Biden and they were actually slightly more likely to prolong than to shorten their viewing of the images of both Barack and Michelle Obama. These same Republican participants made efforts to prolong viewing of nearly all of the Republican images, including Melania Trump, John McCain, Ted Cruz, Donald Trump, Mike Pence, George W. Bush, and Paul Ryan. One Republican political figure was an exception to the overall pattern: Republican participants were slightly more likely to work to make Mitch McConnell's image go away than to stay on the screen.

Turning to the 75 Democratic participants, they were most eager to shorten exposure to Donald Trump followed by Mike Pence and Ted Cruz. Images of Mitch McConnell, Paul Ryan and Melania Trump generated only modest effort to shorten exposure and images of George W. 
Table 1 Mean keypresses to prolong (positive valence) or shorten (negative valence) exposures to images of politicians by participant partisanship.

\begin{tabular}{lccc}
\hline Democrat political actors & Republican & Democrat & Recognition(\%) \\
Hillary Clinton2 (D) & -32.273 & 12.667 & $99 \%$ \\
Hillary Clinton1 (D) & -31.618 & 16.693 & $99 \%$ \\
Bill Clinton (D) & -20.873 & 0.013 & $93 \%$ \\
Bernie Sanders (D) & -17.927 & 37.133 & $94 \%$ \\
Nancy Pelosi (D) & -13.418 & 6.853 & $51 \%$ \\
Joe Biden (D) & -1.927 & 24.493 & $80 \%$ \\
Barack Obama (D) & 1.745 & 53.76 & $100 \%$ \\
Michelle Obama (D) & 4.109 & 55.013 & $99 \%$ \\
Republican Political Actors & Republican & Democrat & Recognition(\%) \\
Donald Trump1 (R) & 19.2 & -29.707 & $100 \%$ \\
Donald Trump2 (R) & 16.291 & $-27,747$ & $99 \%$ \\
Mike Pence (R) & 20 & -25.133 & $86 \%$ \\
Ted Cruz (R) & 15.8 & -23.52 & $90 \%$ \\
Mitch McConnell (R) & -1.982 & -14.347 & $33 \%$ \\
Paul Ryan (R) & 33.927 & -13.347 & $80 \%$ \\
Melania Trump (R) & 13.473 & -10.547 & $99 \%$ \\
Gw Bush (R) & 25.436 & -6.627 & $97 \%$ \\
John McCain (R) & 15.418 & -2.293 & $84 \%$ \\
& $N 5$ & $N=75$ & $N=130$ \\
\hline
\end{tabular}

Bush and John McCain generated very little activity from Democratic participants. In terms of the images Democrats worked to prolong, Barack and Michelle Obama topped with Bernie Sanders and Joe Biden following. Hillary Clinton was well down the list and Democratic participants made no effort to extend exposure to Bill Clinton.

Table 1 also contains information on the degree to which the participants in our study (Democrats and Republican combined) claimed to recognize these 15 political figures. Since we did not want behaviors influenced by political images that were less than completely familiar to the respondents, the remainder of our analyses will focus on only the four Republican political figures (George W. Bush, Melania Trump, and Donald Trump twice) and the four Democratic political figures (Barack Obama, Michelle Obama, and Hillary Clinton twice) who were recognized by at least $97 \%$ of the respondents.

For each participant, we averaged keypress activity for the four political figures of their own and for the four of the other political party and the results are presented in the first two bars of Fig. 2. They show 


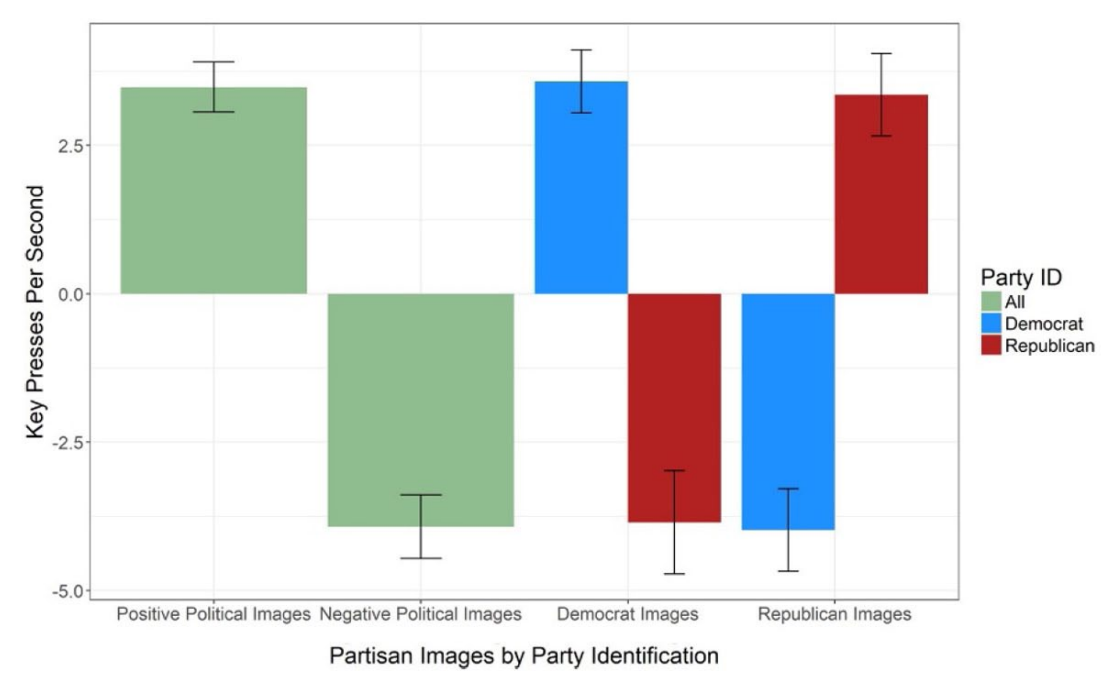

Fig. 2. Keypress activity during viewing images of politicians.

that on average participants made an effort to prolong viewing of political figures of their own party (an average of 3.5 keypresses per second of viewing) and that they also made an effort to shorten exposure to political figures of the opposing political party (an average of 3.9 keypresses per second of viewing). The difference between these two figure types is not statistically significant $(p=.20)$ thus suggesting that negative political stimuli elicit a similar amount of effort as positive stimuli. Remember, however, that the communication literature indicates people are more likely to embrace positive information than to avoid negative information (Garrett, 2009; 2013). It may be the case, however, that when no new information is available (as was true for our participants since they were only looking at facial images) people are freed from the feeling that they should pay more attention to the other side in hopes of garnering information.

Fig. 2 also presents the results broken down by party and here we find that, compared to Republican participants, Democratic participants made more of an effort to prolong exposure to political figures of their political party and that they also made more of an effort to shorten exposure to political figures of the opposing political party. Note, however, that these differences did not achieve statistical significance and are produced by images that are not perfectly balanced across parties (it appears the Obamas were particularly appealing to this undergraduate sample, regardless of their party identification). 
Moving to individual-level analyses, we first calculated each participant's mean effort with regard to generic images (10 positive and 10 negative) and mean effort with regard to the images of political figures ( 4 own-party and 4 other-party). These variables indicate that those participants making the most effort to prolong their viewing of positive generic images also exerted the most effort to shorten viewing of a negative generic image $(r=-0.44 ; p<.01)$. A similar pattern was observed for images of own-party and other-party political figures $(r=-0.53$; $p<$ .01). Moreover, keypress activity to prolong viewing images that are generically positive correlates with keypress activity to prolong viewing images that are politically positive (i.e., own-party political figures) at $0.47(p<.01)$ and keypress activity to shorten exposure to images that are generic but negative correlates with keypress activity to shorten exposure to images that are politically negative (i.e., images of other-party political figures), albeit at a slightly weaker $0.26(p<.01)$.

Next, using participants' self-report of the valence of their response to each image, we correlated the valence self-reports with effort made to prolong or abbreviate viewing of those same images. Keypress behavior for positive generic images was correlated with the valence rating for the same images $(r=0.40 ; p<.01)$ and the same pattern was observed for negative generic images $(r=0.42 ; p<.01)$, images of own party politicians $(r=0.29 ; p<.01)$, and images of other party politicians $(r=0.60$; $p<.01)$. Though clearly related, the modest correlations suggest that efforts to prolong or shorten exposure to images are not the same thing as people's self-reported evaluations.

Our final analysis involves identifying individual-level variables that might be related to the various forms of keypress effort we have been describing. To facilitate presentation of the results, we model them in an OLS regression format, fully recognizing that these are correlational data and permit no certainty about causal order. Explanatory variables include demographic, political, and psychological variables. The four dependent variables are keypresses in response to generic positive images, absolute value of keypresses in response to generic negative images; keypresses in response to political figures of the participant's own party, and absolute value of keypresses in response to political figures of the opposing political party. ${ }^{1}$

1 Residuals for each of the models were normally distributed. A post hoc power analysis indicated a $99 \%$ chance of detecting an effect size larger than 0.5 and only a $20 \%$ chance of detecting a small effect size of $r=0.1$. 
The demographic independent variables are family income, religiosity, sex (female), and race (only 19 of our 130 participants identified as non-white). We did not include education and age since, with a student sample, variation on these particular variables is minimal. The political variables in the models are party identification $(1=$ Republican; $0=$ Democrat) and ideological extremity. The latter was constructed by tabulating the participant's tendency to take "strong" positions (regardless

Table 2 Explaining variation in keypress activity during viewing of positive and negative generic and political images.

\begin{tabular}{|c|c|c|c|c|}
\hline Dependent variable: & $\begin{array}{c}\text { Positive } \\
\text { generic }\end{array}$ & $\begin{array}{r}\text { Negative } \\
\text { generic }\end{array}$ & $\begin{array}{l}\text { Positive } \\
\text { political }\end{array}$ & $\begin{array}{r}\text { Negative } \\
\text { political }\end{array}$ \\
\hline Income & $\begin{array}{l}-0.014 \\
(0.043)\end{array}$ & $\begin{array}{l}-0.004 \\
(0.051)\end{array}$ & $\begin{array}{l}-0.032 \\
(0.055)\end{array}$ & $\begin{array}{l}=0.119^{*} \\
(0.071)\end{array}$ \\
\hline Religiosity & $\begin{array}{c}0.116 \\
(0.177)\end{array}$ & $\begin{array}{c}0.004 \\
(0.209)\end{array}$ & $\begin{array}{l}-0.077 \\
(0.225)\end{array}$ & $\begin{array}{l}-0.116 \\
(0.293)\end{array}$ \\
\hline Female & $\begin{array}{l}-0.082 \\
(0.412)\end{array}$ & $\begin{array}{c}0.529 \\
(0.487)\end{array}$ & $\begin{array}{c}0.170 \\
(0.524)\end{array}$ & $\begin{array}{c}0.635 \\
(0.682)\end{array}$ \\
\hline White & $\begin{array}{c}0.812 \\
(0.493)\end{array}$ & $\begin{array}{c}0.121 \\
(0.582)\end{array}$ & $\begin{array}{c}1.221 * \\
(0.627)\end{array}$ & $\begin{array}{c}0.5465 \\
(0.814)\end{array}$ \\
\hline Republicans & $\begin{array}{c}0.517 \\
(0.418)\end{array}$ & $\begin{array}{l}1.070^{* *} \\
(0.493)\end{array}$ & $\begin{array}{c}0.254 \\
(0.531)\end{array}$ & $\begin{array}{c}0.782 \\
(0.690)\end{array}$ \\
\hline Ideological Extremity & $\begin{array}{c}0.553^{*} \\
(0.281)\end{array}$ & $\begin{array}{c}0.353 \\
(0.332)\end{array}$ & $\begin{array}{c}0.911^{* *} \\
(0.357)\end{array}$ & $\begin{array}{l}1.388^{* * *} \\
(0.465)\end{array}$ \\
\hline Extraversion & $\begin{array}{c}0.077 \\
(0.116)\end{array}$ & $\begin{array}{c}0.221 \\
(0.137)\end{array}$ & $\begin{array}{c}0.187 \\
(0.148)\end{array}$ & $\begin{array}{l}-0.050 \\
(0.192)\end{array}$ \\
\hline Agreeableness & $\begin{array}{l}0.492^{* * *} \\
(0.161)\end{array}$ & $\begin{array}{c}0.204 \\
(0.137)\end{array}$ & $\begin{array}{c}0.267 \\
(0.205)\end{array}$ & $\begin{array}{c}0.074 \\
(0.267)\end{array}$ \\
\hline Emotional Stability & $\begin{array}{l}-0.128 \\
(0.163)\end{array}$ & $\begin{array}{l}-0.146 \\
(0.192)\end{array}$ & $\begin{array}{l}-0.312 \\
(0.207)\end{array}$ & $\begin{array}{c}0.027 \\
(0.269)\end{array}$ \\
\hline Openness & $\begin{array}{l}-0.239 \\
(0.182)\end{array}$ & $\begin{array}{l}-0.004 \\
(0.215)\end{array}$ & $\begin{array}{l}-0.329 \\
(0.231)\end{array}$ & $\begin{array}{c}0.012 \\
(0.300)\end{array}$ \\
\hline Conscientiousness & $\begin{array}{c}0.078 \\
(0.169)\end{array}$ & $\begin{array}{c}0.228 \\
(0.200)\end{array}$ & $\begin{array}{c}0.360^{*} \\
(0.215)\end{array}$ & $\begin{array}{c}0.346 \\
(0.280)\end{array}$ \\
\hline BIS & $\begin{array}{c}0.124 \\
(0.202)\end{array}$ & $\begin{array}{r}0.409^{*} \\
(0.238)\end{array}$ & $\begin{array}{l}-0.354 \\
(0.256)\end{array}$ & $\begin{array}{l}-0.302 \\
(0.333)\end{array}$ \\
\hline BAS & $\begin{array}{c}0.469^{*} \\
(0.272)\end{array}$ & $\begin{array}{l}-0.258 \\
(0.321)\end{array}$ & $\begin{array}{c}0.188 \\
(0.346)\end{array}$ & $\begin{array}{l}-0.060 \\
(0.450)\end{array}$ \\
\hline Constant & $\begin{array}{l}-1.573 \\
(2.090)\end{array}$ & $\begin{array}{c}1.485 \\
(2.468)\end{array}$ & $\begin{array}{c}1.713 \\
(2.657)\end{array}$ & $\begin{array}{c}2.349 \\
(3.545)\end{array}$ \\
\hline Observation & 128 & 128 & 128 & 128 \\
\hline$R^{2}$ & 0.172 & 0.180 & 0.155 & 0.139 \\
\hline Adjusted $R^{2}$ & 0.077 & 0.086 & 0.059 & 0.041 \\
\hline
\end{tabular}

${ }^{*} p<0.05 ;{ }^{* *} p<0.01 ;{ }^{* * *} p<0.001$ 
of direction) on 25 political issues. We included two psychological batteries in the models. The first is the 10- item TIPI battery that taps the Big 5 personality constructs and the second is the well-known BIS/BAS 24 item battery.

The results show that remarkably few of these variables are significant predictors of keypress effort. Starting with effort in response to generic positive images (column 1), only issue extremity and behavioral activation (BAS) have marginal effects $(p<.10)$ and only agreeableness has a solid effect $(p<.05)$. The model for keypress effort to shorten viewing of generic negative images does no better. As might have been expected with a shift from positive to negative, the behavioral activation variable drops out and behavioral inhibition is instead marginally related ( $p<$ .10). The only variable in this model that is statistically significant at the 0.05 level is identification with the Republican Party. Compared to Democrats, Republican participants made more effort to minimize exposure to negative generic stimuli.

The models dealing with effort to prolong viewing of own-party political figures (column 3) and to shorten viewing of other-party political figures (column 4)-are similarly underspecified. The only significant variable in both Models 3 and 4 is issue extremity. The positive sign indicates that greater issue position strength is typically accompanied by greater effort to prolong viewing of own-party political figures. Interestingly, the effect for effort to minimize exposure to other party images is nearly a third larger, suggesting that as issue positions move from the center, the desire to minimize exposure to the opposing party goes up faster that the desire to maximize exposure to their own party. ${ }^{2}$

\section{Conclusion}

The keypress measure introduced above is not perfectly reflective of real-world situations, but it does allow individuals to either maintain or navigate away from political images just as they are able to do through on-line media sources. The ubiquity of politics within social media platforms makes it more important to understand the amount of effort people are willing to expend to engage in motivated viewing. This

2 We tested the issue extremity by partisanship interaction for each of the models. The interaction was insignificant in all four models $(p>.39)$. 
continuous, controllable measure of effort makes it possible to separate reinforcement seeking from challenge avoidance behaviors, just as it makes it possible to remove affective content from policy information. Our analysis using this measure finds those with strong positions on various political issues tend to be more eager to diminish their exposure to political opponents than to increase their exposure to fellow partisans. The fact that the focus of those with strong political beliefs shifts to the opposing side could be an important contributing factor to political polarization and acrimony.

Still, the larger message here is that people are not merely engaging in selective exposure because of informational concerns. They do it because they want to. Previous research using substantive information finds that reinforcement seeking is a stronger force than challenge avoidance (Garrett, 2009). Our results using only still images and not substantive information suggest that, if anything, the desire to avoid the politically negative is equal to the desire to be exposed to the positive.

If generalizable, this finding suggests that selective exposure in the political realm is about much more than shaping information environments. When people have no appreciable opportunity to glean substantive information from political content, they still expend effort to prolong their exposure to images consistent with their biases and to minimize their exposure to those on the other side of the political arena. Since there is no opportunity for contravening information, people's tendency to engage in affective selective exposure takes on a life of its own, further degrading political interactions.

\section{Supplementary materials}

Supplementary material follows the References.

\section{References}

Arceneaux, K., \& Johnson, M. (2013). Changing minds or changing channels?: Partisan news in an age of choice. Chicago, IL: University of Chicago Press.

Bakker, B. N., Hopmann, D. N., \& Persson, M. (2015). Personality traits and party identification over time. European Journal of Political Research, 54(2), 197-215.

Brandt, M. J., Reyna, C., Chambers, J. R., Crawford, J. T., \& Wetherell, G. (2014). The ideological-conflict hypothesis: Intolerance among both liberals and conservatives. Current Directions in Psychological Science, 23(1), 27-34. 
Brockner, J., \& Higgins, E. T. (2001). Regulatory focus theory: Implications for the study of emotions at work. Organizational behavior and human decision processes, 86(1), 35-66.

Carver, C. S., \& White, T. L. (1994). Behavioral inhibition, behavioral activation, and affective responses to impending reward and punishment: The bis/bas scales. Journal of Personality and Social Psychology, 67, 319-333.

Crawford, J., Modri, S., \& Motyl, M. (2013). Bleeding-heart liberals and hard-hearted conservatives: Subtle political dehumanization through differential attributions of human nature and human uniqueness traits. Available at SSRN 2310758.

Crigler, A. N., \& Heveron, P. R. (2017). Affect and political choice. In K. Kenski, \& K. H. Jamieson (Eds.). The Oxford handbook of political communication (pp. 663-682). New York, NY: Oxford University Press.

DeYoung, C. G., Quilty, L. C., \& Peterson, J. B. (2007). Between facets and domains: 10 aspects of the big five. Journal of Personality and Social Psychology, 93, 880-896.

DiMaggio, P., \& Sato, K. (2003). Does the internet balkanize attention? Paper presented at the annual meeting of the American sociological association. Atlanta, GA: Atlanta Hill Hotel.

Dubois, E., \& Blank, G. (2018). The echo chamber is overstated: The moderating effect of political interest and diverse media. Information, Communication \& Society, 21(5), 729-745.

Feldman, L., Stroud, N. J., Bimber, B., \& Wojcieszak, M. (2013). Assessing selective exposure in experiments: The implications of different methodological choices. Communication Methods and Measures, 7(3-4), 172-194.

Feltman, R., \& Elliot, A. J. (2012). Approach and avoidance motivation. Encyclopedia of the sciences of learning. New York City, NY: Springer286-288.

Festinger, L. (1957). A theory of cognitive dissonance. Stanford, CA: Stanford University Press.

Frey, D. (1986). Recent research on selective exposure to information. Advances in Experimental Social Psychology, 19, 41-80.

Garrett, R. K. (2009). Politically motivated reinforcement seeking: Reframing the selective exposure debate. Journal of communication, 59(4), 676-699.

Garrett, R. K. (2013). Selective exposure: New methods and new directions. Communication Methods and Measures, 7(3-4), 247-256.

Gerber, A. S., Huber, G. A., Doherty, D., \& Dowling, C. M. (2012). Personality and the strength and direction of partisan identification. Political Behavior, 34(4), 653-688.

Gerber, A. S., Huber, G. A., Doherty, D., Dowling, C. M., \& Ha, S. E. (2010). Personality and political attitudes: Relationships across issue domains and political contexts. American Political Science Review, 104(1), 111-133.

Hart, W., Albarracín, D., Eagly, A. H., Brechan, I., Lindberg, M. J., \& Merrill, L. (2009). Feeling validated versus being correct: A meta-analysis of selective exposure to information. Psychological bulletin, 135(4), 555-588.

Holtzman, N., Schott, J., Jones, M., Balota, D., \& Yarkoni, T. (2011). Exploring media bias with semantic analysis tools. Behavior Research Methods, 4(3), 193-200. 
Huckfeldt, R. R., Johnson, P. E., \& Sprague, J. (2004). Political disagreement: The survival of diverse opinions within communication networks. Cambridge: Cambridge University Press.

Jost, J. T., \& Amodio, D. M. (2012). Political ideology as motivated social cognition: Behavioral and neuroscientific evidence. Motivation and Emotion, 36(1), 55-64.

Kahneman, D., \& Tversky, A. (1984). Choices, values, and frames. American Psychologist, 39(4), 341.

Kim, B. W., Kennedy, D. N., Lehár, J., Lee, M. J., Blood, A. J., Lee, S., et al. (2010). Recurrent, robust and scalable patterns underlie human approach and avoidance. PloS one, 5(5), e10613.

Knobloch-Westerwick, S., \& Kleinman, S. B. (2012). Preelection selective exposure: Confirmation bias versus informational utility. Communication Research, 39(2), 170-193.

Lang, P. J., Bradley, M. M., \& Cuthbert, B. N. (1997). International affective picture system (IAPS): Technical manual and affective ratings. NIMH Center for the Study of Emotion and Attention, 39-58.

Lee, S., Lee, M. J., Kim, B. W., Gilman, J. M., Kuster, J. K., Blood, A. J., et al. (2015). The commonality of loss aversion across procedures and stimuli. PloS one, 10(9), e0135216.

Leeper, T. J., \& Mullinix, K. J. (2018). Motivated reasoning. In L. S. Maisel (Ed.). Oxford bibliographies in political science (pp. 129-156). New York, NY: Oxford University Press.

Lodge, M., \& Taber, C. S. (2005). The automaticity of affect for political leaders, groups, and issues: An experimental test of the hot cognition hypothesis. Political Psychology, 26(3), 455-482.

Lodge, M., \& Taber, C. S. (2013). The rationalizing voter. New York, NY: Cambridge University Press.

Marquart, F., Matthes, J., \& Rapp, E. (2016). Selective exposure in the context of political advertising. International Journal of Communication, 10, 2576-2595.

Mondak, J. J., Hibbing, M. V., Canache, D., Seligson, M. A., \& Anderson, M. R. (2010). Personality and civic engagement: An integrative framework for the study of trait effects on political behavior. American Political Science Review, 104(1), 85-110.

Mutz, D. C. (2002). The consequences of cross-cutting networks for political participation. American Journal of Political Science, 46(4), 838-855.

Mutz, D. C. (2006). Hearing the other side: Deliberative versus participatory democracy. New York: Cambridge University Press.

Oosterhoff, B., Shook, N. J., \& Ford, C. (2018). Is that disgust I see? Political ideology and biased visual attention. Behavioural Brain Research, 336, 227-235.

Oxley, D. R., Smith, K. B., Alford, J. R., Hibbing, M. V., Miller, J. L., Scalora, M., et al. (2008). Political attitudes vary with physiological traits. Science, 321(5896), 1667-1670.

Peeters, G., \& Czapinski, J. (1990). Positive-negative asymmetry in evaluations: The distinction between affective and informational negativity effects. European review of social psychology, 1(1), 33-60. 
Shook, N. J., \& Fazio, R. H. (2009). Political ideology, exploration of novel stimuli, and attitude formation. Journal of Experimental Social Psychology, 45(4), 995-998.

Soroka, S., Fournier, P., Nir, L., \& Hibbing, J. (2019). Psychophysiology in the study of political communication: An expository study of individual-level variation in negativity biases. Political Communication, 36(2), 288-302.

Soroka, S., \& McAdams, S. (2015). News, politics, and negativity. Political Communication, 32(1), 1-22.

Sunstein, C. R. (2001). Republic.com. Princeton, NJ: Princeton University Press. 


\section{Motivated Viewing: \\ Selective Exposure to Political Images When Reasoning is not Involved \\ Supporting Information}

August 5, 2019

\section{Contents}

$1 \quad$ Replication Student Sample Description

$\begin{array}{lll}2 & \text { Tables } & 4\end{array}$

\begin{tabular}{|lll}
\hline 3 & Figures & 7 \\
\hline
\end{tabular}

4 Keypress Task 9 


\section{List of Tables}

S1 Student Sample: Descriptive Statistics . . . . . . . . . . . . . . . . . . . . . . . . . 4

S2 $\quad$ Second Student Sample: Descriptive Statistics . . . . . . . . . . . . . . . . . . . . . . . . . . . 4

S3 Second Student Sample: Mean Keypresses to Prolong (Positive Valence) or Shorten (Negative Valence) Exposures to Images of Politicians by Participant Partisanship . . . . . . . . . . . . . 5

S4 Second Student Sample: Correlations of Keypress Behavior and Self-Reported Valence Ratings 6

\section{List of Figures}

$1 \quad$ Second Student Sample: Keypress Activity during Viewing of Positive and Negative Generic

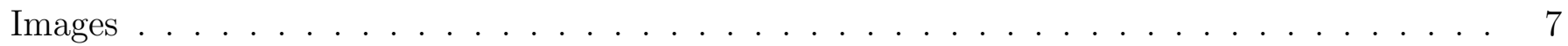

$2 \quad$ Second Student Sample: Keypress Activity during Viewing Images of Politicians . . . . . . . . 8 


\section{Replication Student Sample Description}

A second student sample consisted of 105 students enrolled in introductory-level political science classes in Spring of 2019. Participants in the second sample completed the same task as those in first student sample reported in manuscript. Results from the second student sample are presented below (Tables S2 to S4 and Figures 1 and 2) and reveal a pattern consistent with the results from the first student sample reported in the manuscript. 


\section{Tables}

Table S1: Student Sample: Descriptive Statistics

\begin{tabular}{lccccccc}
\hline \hline Statistic & $\mathrm{N}$ & Mean & St. Dev. & Min & Pctl(25) & Pctl(75) & Max \\
\hline Positive Generic Keypresses* $^{*}$ & 137 & 4.170 & 1.978 & 0.087 & 2.646 & 5.790 & 8.325 \\
Negative Generic Keypresses* & 137 & 5.729 & 2.275 & 0.190 & 4.189 & 7.470 & 10.033 \\
Income & 137 & 8.956 & 4.213 & 1.000 & 6.000 & 12.000 & 15.000 \\
Religiosity & 138 & 2.435 & 1.107 & 1 & 2 & 3 & 4 \\
Female & 138 & 0.565 & 0.498 & 0 & 0 & 1 & 1 \\
White & 136 & 0.853 & 0.355 & 0.000 & 1.000 & 1.000 & 1.000 \\
Ideological Extremity & 138 & 0.919 & 0.670 & 0.000 & 0.360 & 1.350 & 2.680 \\
Extraversion & 138 & 4.301 & 1.622 & 1 & 3.5 & 5.5 & 7 \\
Agreeableness & 138 & 4.692 & 1.129 & 1 & 4 & 5.5 & 7 \\
Emotional Stability & 138 & 4.696 & 1.351 & 1 & 4 & 6 & 7 \\
Openness & 138 & 5.228 & 1.113 & 2.000 & 4.500 & 6.000 & 7.000 \\
Conscientiousness & 138 & 5.572 & 1.087 & 2.500 & 5.000 & 6.500 & 7.000 \\
BIS & 138 & 4.711 & 1.096 & 2.000 & 4.000 & 5.500 & 7.000 \\
BAS & 138 & 5.185 & 0.733 & 3.308 & 4.635 & 5.692 & 7.000 \\
\hline
\end{tabular}

Note: ${ }^{*}=$ per second; ${ }^{* *}=$ per second absolute value height

Table S2: Second Student Sample: Descriptive Statistics

\begin{tabular}{lccccccc}
\hline \hline Statistic & $\mathrm{N}$ & Mean & St. Dev. & Min & Pctl(25) & Pctl(75) & Max \\
\hline Positive Generic Keypresses* & 105 & 2.996 & 2.092 & 0.000 & 1.199 & 4.813 & 6.700 \\
Negative Generic Keypresses** & 105 & 4.705 & 2.509 & 0.013 & 3.039 & 6.707 & 9.471 \\
Income & 103 & 8.709 & 4.528 & 1.000 & 5.000 & 12.000 & 15.000 \\
Religiosity & 105 & 2.219 & 1.168 & 1 & 1 & 3 & 4 \\
Female & 105 & 0.438 & 0.499 & 0 & 0 & 1 & 1 \\
White & 105 & 0.743 & 0.439 & 0 & 0 & 1 & 1 \\
Ideological Extremity & 83 & 0.889 & 0.653 & 0.000 & 0.408 & 1.240 & 2.640 \\
Extraversion & 82 & 4.341 & 1.474 & 1.000 & 3.500 & 5.500 & 7.000 \\
Agreeableness & 82 & 4.695 & 1.196 & 1.500 & 4.000 & 5.500 & 7.000 \\
Emotional Stability & 82 & 4.835 & 1.315 & 1.500 & 4.000 & 6.000 & 7.000 \\
Openness & 82 & 5.226 & 1.240 & 2.000 & 4.500 & 6.000 & 7.000 \\
Conscientiousness & 82 & 4.884 & 1.268 & 2.000 & 4.000 & 6.000 & 7.000 \\
BIS & 74 & 4.687 & 0.999 & 1.500 & 4.167 & 5.333 & 6.667 \\
BAS & 74 & 5.249 & 0.742 & 3.308 & 4.769 & 5.846 & 6.769 \\
\hline
\end{tabular}

Note: ${ }^{*}=$ per second; ${ }^{* *}=$ per second absolute value height 
Table S3: Second Student Sample: Mean Keypresses to Prolong (Positive Valence) or Shorten (Negative Valence) Exposures to Images of Politicians by Participant Partisanship

\begin{tabular}{|c|c|c|c|}
\hline Political Actor & Republican & Democrat & Recognition (\%) \\
\hline Hillary Clinton2 (D) & -23.279 & -9.230 & $99 \%$ \\
\hline Hillary Clinton1 (D) & -23.209 & -4.902 & $99 \%$ \\
\hline Bernie Sanders (D) & -20.884 & 20.803 & $85 \%$ \\
\hline Nancy Pelosi (D) & -15.977 & 0.721 & $73 \%$ \\
\hline Bill Clinton (D) & -15.256 & -3.361 & $92 \%$ \\
\hline Joe Biden (D) & -8.628 & 12.672 & $70 \%$ \\
\hline Mitch McConnell (R) & -7.186 & -13.721 & $42 \%$ \\
\hline Barack Obama (D) & -2.395 & 35.049 & $100 \%$ \\
\hline Michelle Obama (D) & 0.209 & 38.902 & $99 \%$ \\
\hline GW Bush (R) & 1.419 & -7.885 & $91 \%$ \\
\hline John McCain (R) & 3.698 & 0.754 & $75 \%$ \\
\hline Ted Cruz (R) & 4.977 & -20.443 & $86 \%$ \\
\hline Mike Pence (R) & 5.488 & -19.197 & $76 \%$ \\
\hline Paul Ryan (R) & 8.023 & -10.607 & $72 \%$ \\
\hline Donald Trump2 (R) & 8.674 & -27.754 & $100 \%$ \\
\hline Melania Trump (R) & 13.070 & -14.721 & $98 \%$ \\
\hline \multirow[t]{2}{*}{ Donald Trump1 (R) } & 13.140 & -28.525 & $100 \%$ \\
\hline & $\mathrm{N}=43$ & $\mathrm{~N}=61$ & $\mathrm{~N}=104$ \\
\hline
\end{tabular}


Table S4: Second Student Sample: Correlations of Keypress Behavior and Self-Reported Valence Ratings

\begin{tabular}{lc}
\hline \hline Prolong Keypresses - Shorten Keypresses (Generic Images) & $-0.52^{* * *}$ \\
Prolong Keypresses - Shorten Keypresses (Images of Politicans) & $-0.45^{* * *}$ \\
Prolong Keypresses (Positive Generic Images) - Prolong Keypresses (Images of Own-Party Politicians) & $0.32^{* * *}$ \\
Shorten Keypresses (Negative Generic Images) - Shorten Keypresses (Images of Other-Party Politicians) & 0.15 \\
& \\
Keypress Behavior - Valence Rating (Positive Generic Images) & $0.48^{* * *}$ \\
Keypress Behavior - Valence Rating (Negative Generic Images) & $0.58^{* * *}$ \\
Keypress Behavior - Valence Rating (Images of Own Party Politicians) & $0.28^{* * *}$ \\
Keypress Behavior - Valence Rating (Images of Other Party Politicians) & $0.60^{* * *}$ \\
\hline \hline Note: Negative Generic and Other-Party: $p=0.11$ & ${ }^{*} \mathrm{p}<0.1 ;{ }^{* *} \mathrm{p}<0.05 ;{ }^{* * *} \mathrm{p}<0.01$
\end{tabular}




\section{$3 \quad$ Figures}

Figure 1: Second Student Sample: Keypress Activity during Viewing of Positive and Negative Generic Images

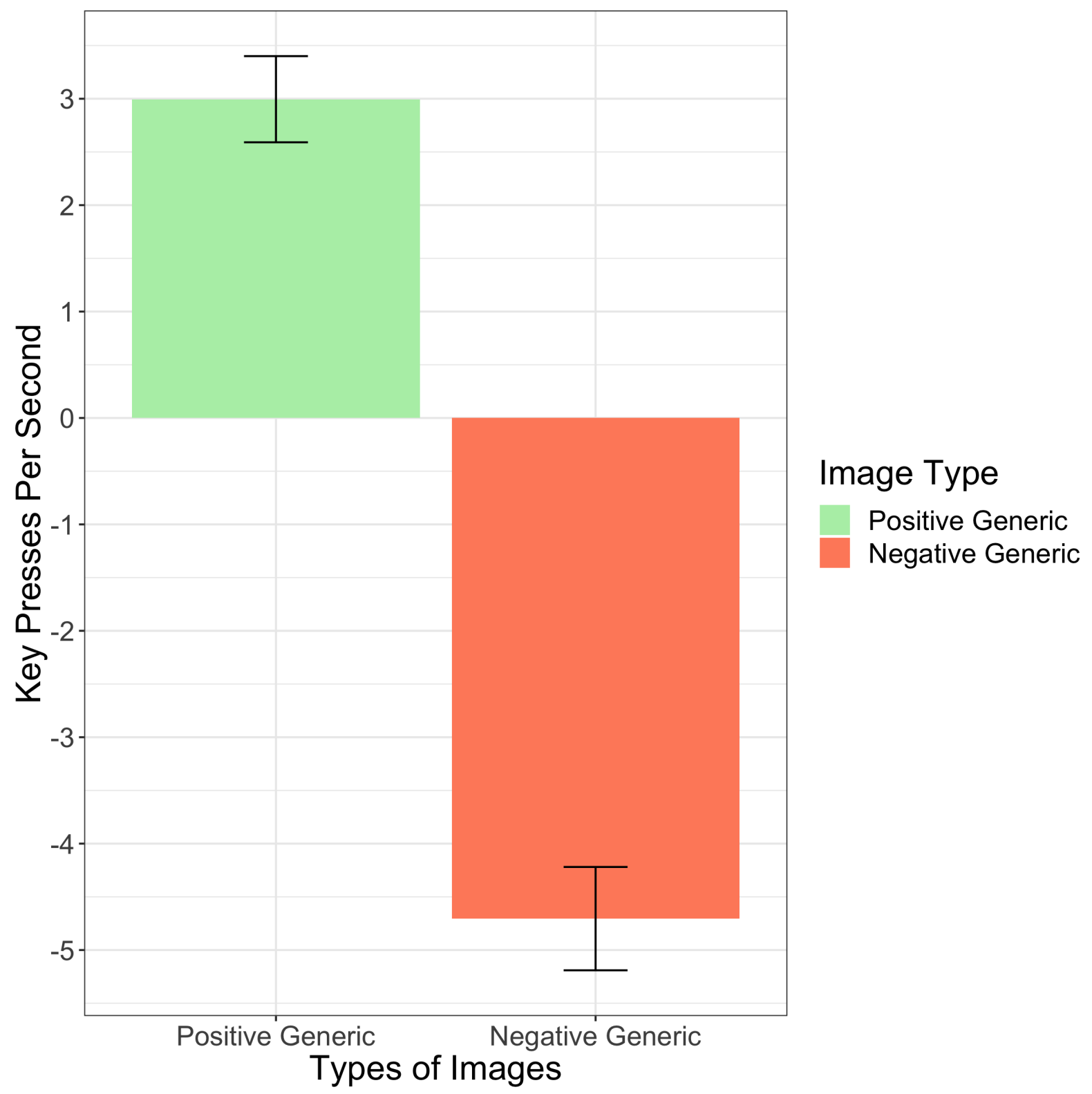


Figure 2: Second Student Sample: Keypress Activity during Viewing Images of Politicians

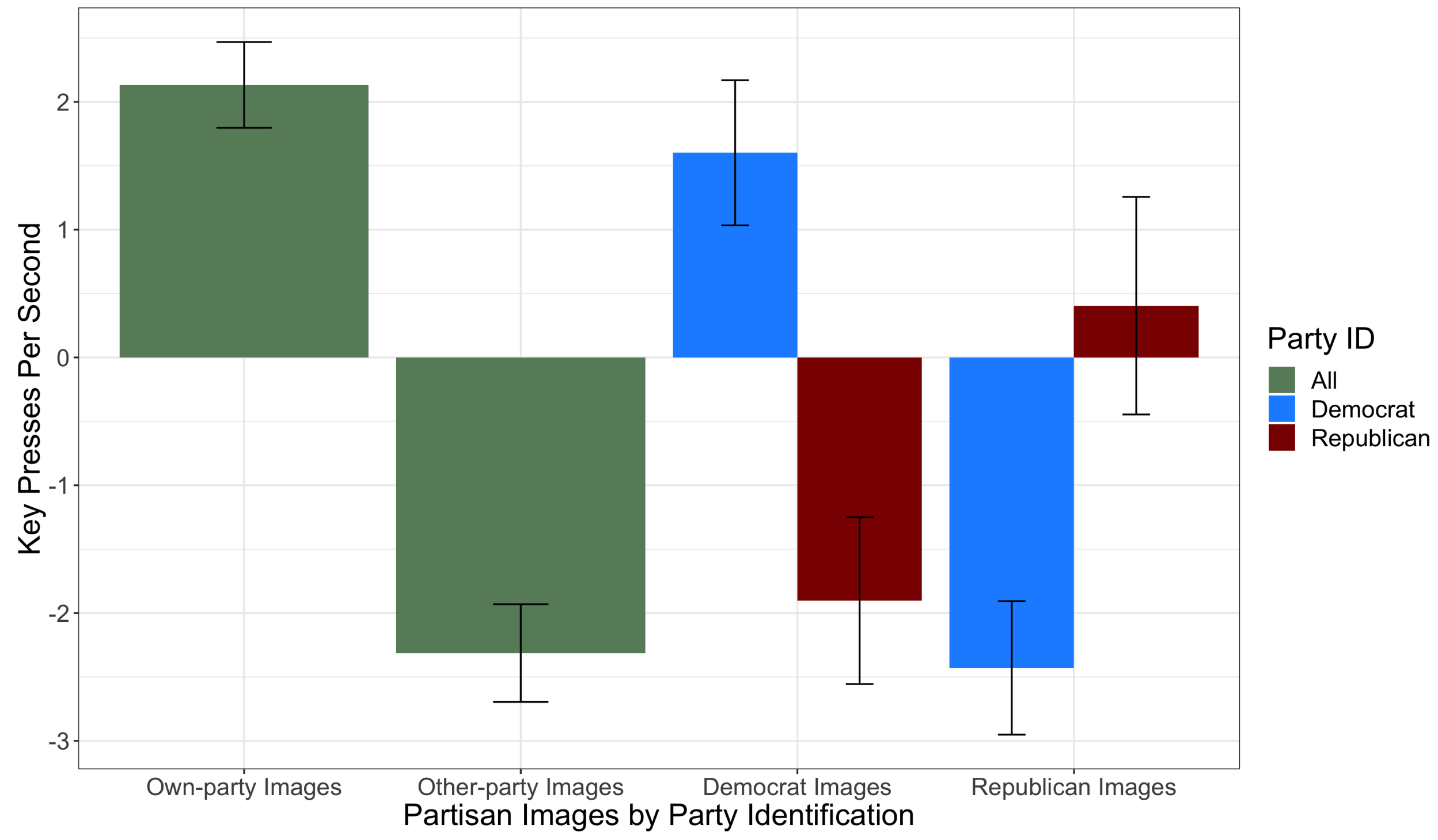




\section{Keypress Task}

The code to run the keypress task is available from the authors.

All but three of the generic images came from IAPS. Three animal images were added to the positive generic set of images to balance the positive and generic images on mean arousal and valence. The reference numbers for the IAPS images selected are listed below.

IAPS Image Reference Numbers:

- 1300

- 1440

- 1710

- 2071

- 5480

- 5621

- 5833

- 6260

- 6550

- 6570

- 6821

- 8200

- 9008

- 9140

- 9301

- 9320

- 9405 